ORIGINAL ARTICLE

\title{
Assessing automobile head restraint positioning in Portland, Oregon
}

\author{
A L Young, B T Ragel, E Su, C N Mann, E H Frank
}

Injury Prevention 2005;11:97-101. doi: 10.1136/ip.2004.006122

See end of article for authors' affiliations

.....................

Correspondence to:

Dr E H Frank, Department

of Neurosurgery, Oregon

Health Sciences University,

3181 SW Sam Jackson

Road, L472, Portland, OR

97201, USA; franke@

ohsu.edu

\begin{abstract}
Objective: Automobile head restraints, when used properly, have been shown to decrease the incidence and severity of whiplash injuries to the neck. Before the development of a public campaign on proper head restraint positioning, the authors assessed head restraint positioning and public understanding.

Design: Over a one month period, the position of the vehicle head restraint of drivers was observed in moving cars in the city of Portland, Oregon (population 530 000). Optimal position was defined as having the head restraint above the ears with the back of the head touching the head restraint. A questionnaire on head restraint understanding was administered to people during jury service.

Results: Of the 4287 drivers observed, 1\% $(n=30)$ had no head restraint on their seat, $4 \%(n=158)$ had a fixed head restraint, and $95 \%(n=4099)$ had an adjustable head restraint. Among the fixed head restraints, $21 \%(33 / 158)$ were positioned optimally with no horizontal gap. Among the adjustable head restraints, only 7\% (280/4099) had optimal head restraint positioning. Overall, 93\% (3974/4287) of all head restraints observed were suboptimally positioned. Seventy five percent (38/51) of polled Portland residents identified safety as the primary head restraint function.

Conclusion: Ninety three percent of all head restraints observed were suboptimally positioned. Fixed head restraints were three times more likely to be in optimal position than adjustable head restraints (21\% v $7 \%$ ). Most polled Portland residents understood the proper function and positioning of head restraints. This discrepancy between actual practice and understanding should be addressed with public education and manufacturer design changes.
\end{abstract}

$\mathrm{T}$ he terms "whiplash" and "whiplash associated disorders" are used to describe neck injuries related to sudden movement of the neck. Characteristic symptoms of whiplash include neck pain, headache, and arm tingling. Whiplash injuries sustained in motor vehicle accidents (MVAs) have become an issue of growing concern. The incidence of whiplash following MVAs ranges from $7 \%$ to $37 \% .^{1-4}$ In 1995, a Canadian study showed that the number one injury for which auto insurance claims are submitted is whiplash. ${ }^{5}$ In 1997, it was estimated that $66 \%$ of all insurance claimants under bodily injury liability coverage and 59\% under personal injury protection coverage reported neck injury. Of these claimants, $42 \%$ and $36 \%$, respectively, reported that neck strain was their most serious injury. The overall cost of just these US claims in 1997 where neck pain was reported as the most serious injury was $\$ 7$ billion. ${ }^{6}$

As early as the 1960s, research indicated that head restraints could prevent whiplash injuries in a rear-end crash. After the United States Department of Transportation mandated head restraints on cars manufactured after 31 December 1968, an 18\% decline in whiplash claims in the US was noted. ${ }^{2}$ In another insurance study, drivers with head restraints rated as "good" by Insurance Institute for Highway Safety (IIHS) criteria were $24 \%$ less likely than drivers with poor head restraints to sustain neck injuries in rear-end crashes. ${ }^{7}$ More recently, seat back and head restraint design changes in Saab, General Motors, and Nissan vehicles have resulted in a $43 \%$ reduction in neck injury claim rates with the new "Active Head Restraints", compared with similar cars before such restraints were introduced. ${ }^{8}$

Head restraints were designed to prevent whiplash by minimizing the neck movement that occurs in MVAs. Although the biomechanics of the cervical spine during MVAs have been well studied, the precise pathologic mechanism by which neck deceleration produces the symptoms of whiplash is unknown. ${ }^{9-11}$ It is, however, universally accepted that the cause of whiplash is the sudden differential, or whip-like, movement of the head and neck relative to the torso. ${ }^{7}$ Evidence that head restraints decrease the incidence of whiplash comes from insurance data. ${ }^{28}$ However, head restraints must be properly positioned to prevent whiplash.

To be effective, a restraint must be positioned behind and close to the back of the person's head. The IIHS uses the criteria for head restraint positioning published by the Research Council for Automobile Repairs. ${ }^{12}$ Head restraints are evaluated based on two criteria. The first is the distance down from the top of the head of an average sized male to the top of the restraint. ${ }^{7}$ A head restraint should be at least as high as the head's center of gravity, or approximately 3.5 inches $(9 \mathrm{~cm})$ below the top of the occupant's head. ${ }^{7}$ The second criterion is the horizontal distance from the back of an average sized male's head to the front of the restraint. A horizontal distance of more than 4 inches $(10 \mathrm{~cm})$ has been associated with increased symptoms of neck injury in MVAs. $^{72}$ Based on the above criteria, the IIHS classifies head restraint positioning based upon four geometric zonesgood, acceptable, marginal, or poor. ${ }^{7}$ The IIHS criteria for good head restraint positioning is supported by biomechanical and observational studies showing benefit with the head restraint behind and close to the back of the head. ${ }^{19-11}$ 13-15

The purpose of this observational study was to assess head restraint positioning and public understanding prior to the development of a public campaign on optimal head restraint positioning in Portland, Oregon.

Abbreviations: MVA, motor vehicle accident; IIHS, Insurance Institute for Highway Safety. 


\section{METHODS}

\section{Study design}

A visual survey of head restraint position was made on drivers of moving cars in the city of Portland, Oregon (population 530 000). According to the findings of a major Canadian study, three conditions characterize the majority of whiplash injuries: (1) the victim is the driver of the vehicle; (2) the type of vehicle is a car or taxi; and (3) the authorized speed limit is $<60 \mathrm{~km} / \mathrm{h}(<38 \mathrm{mph})$. $^{5}$ Although these factors have been related to most whiplash injuries, it has been suggested that these observations may also be a result of direct exposure (that is, most vehicle occupants are drivers, most vehicles are cars, and most travel is probably done in urban areas at moderate speed limits). Given these previous findings, we chose to assess head restraint positioning on only drivers of cars or taxis in zones of $25 \mathrm{mph}$ to $45 \mathrm{mph}$ speed limits. Trucks, vans, and sport utility vehicles were excluded from this study. Data from different types of roadways (residential, commuter, and business) were observed. Driver age and sex, time of day, and specific location were not recorded. No observations were made at night.

A single observer noted head restraint positioning on drivers of all moving vehicles meeting the above criteria passing a single vantage point over a four week period. Observations were made 5-15 feet from moving cars, which enabled differentiation between adjustable and fixed head restraints (see below discussion). Cars were observed along straight sections of road, minimizing the effects that stopping and starting have on head position (that is, flexion and extension of the neck during deceleration or acceleration). Following these rationale, three separate sites were chosen where passing cars could be observed safely from a close distance and traffic was such that all cars could be easily counted (that is, we avoided extremely heavily traveled streets with cars traveling at speeds greater than $45 \mathrm{mph}$ ). The following three sites were chosen:

- A two lane residential street, traveling through a middle class neighborhood, with a posted speed limit of $35 \mathrm{mph}$. All drivers were noted as they traveled in either direction.

- A four lane commuter road, connecting middle and upper class neighborhoods to downtown, with a posted speed limit of $45 \mathrm{mph}$. All drivers were observed as they traveled in either direction.

- A two lane business street with a posted speed limit of $25 \mathrm{mph}$. All drivers were observed in either direction.

\section{Definition of optimal head restraint position}

To assess head restraint positioning, the vertical height of the head restraint and the horizontal gap between the head and the head restraint were assessed (fig 1). Reliably assessing a good horizontal dimension (that is, back of the head less than 4 inches) in a moving vehicle is difficult. For ease of data collection, therefore, we modified the IIHS criteria for a good head restraint position by defining optimal horizontal position as when the back of the head is touching the head restraint. For the purposes of this paper, we use the term "optimal" head restraint positioning to indicate a head restraint level with the ears and touching the back of the head (fig 2), whereas "suboptimal" refers to a head restraint that fails to meet the above criteria (fig 3).

Cars were classified as having no head restraint, a fixed head restraint (for example, Volvo seats with high, nonadjustable head restraints), or an adjustable head restraint (that is, head restraints whose vertical height could be adjusted). Cars with fixed head restraints were assessed for horizontal positioning only, because their construction was

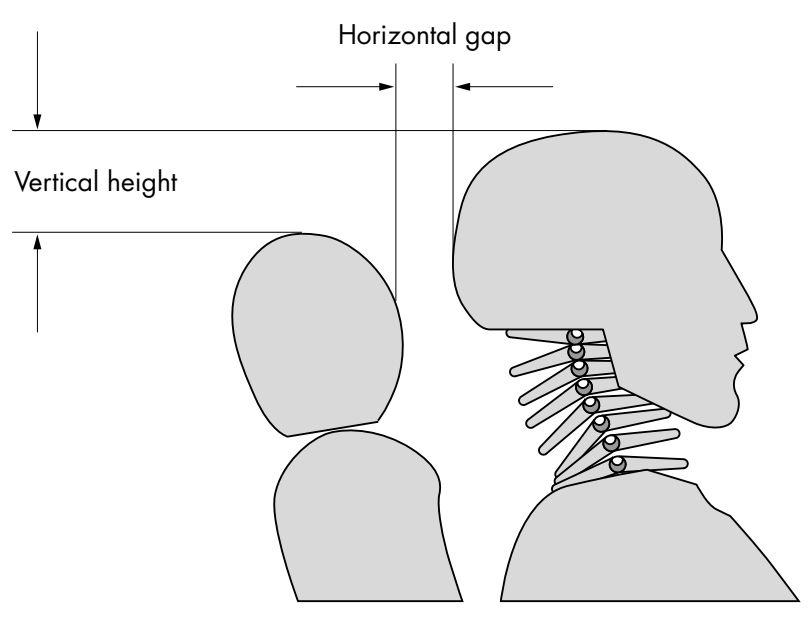

Figure 1 The vertical and horizontal components of the head in relation to the head restraint. Optimal head restraint position was defined as the head restraint located above the ears (vertical height) and touching the back of the head (horizontal gap).

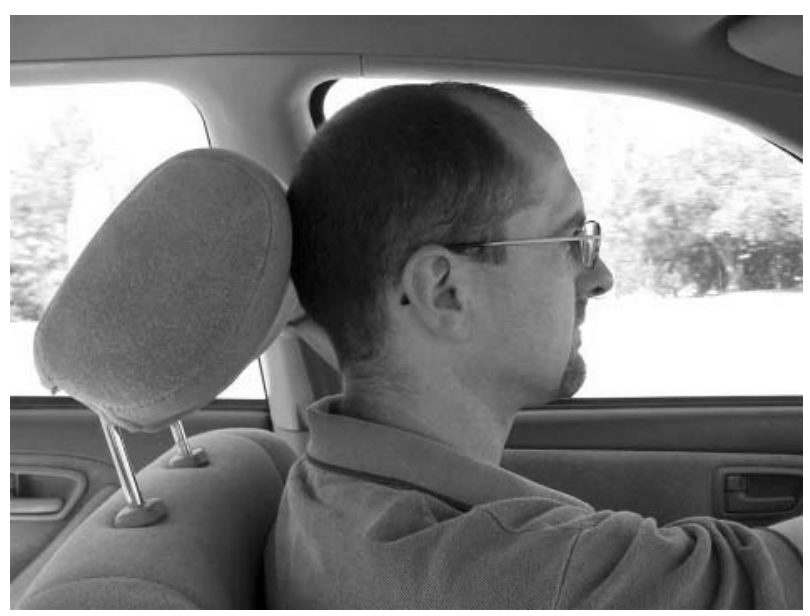

Figure 2 Example of optimal head restraint position. Head restraint is located above the ears and touching the back of the head.

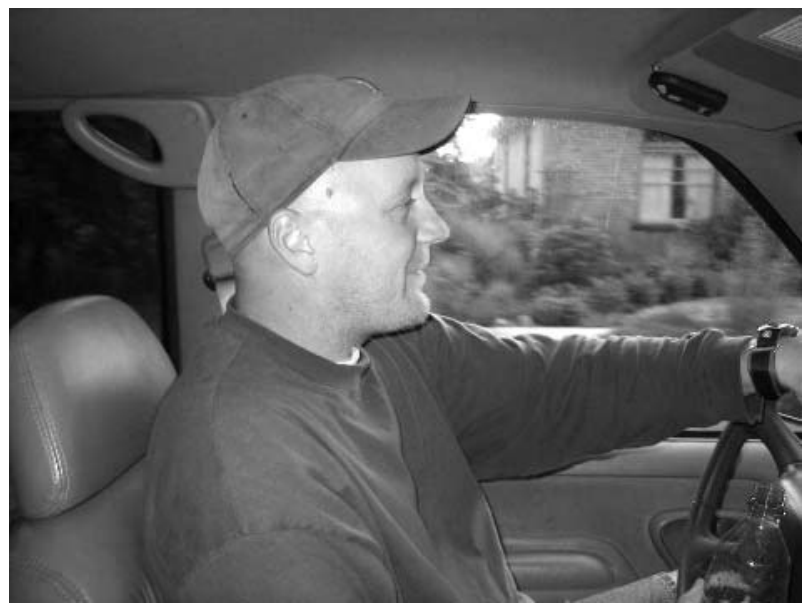

Figure 3 Example of suboptimal head restraint position. Head restraint is located below the ears and not touching the back of the head. 
assumed to ensure adequate vertical height. Cars with adjustable head restraints were assessed for positioning in both the vertical and horizontal planes. Fixed head restraints were defined as those consisting of a single solid structure behind the driver's head, whereas adjustable head restraints were noted to contain an adjustable pole at the base.

\section{Questionnaire}

A sample of Portland residents were polled during their mandatory jury service week on head restraint type, function, and proper positioning. This sample was considered to be representative of all Portland residents although demographic statistics were not measured. The court system of Multnomah County (including Portland) compiles a list of potential jurors from lists of registered voters, licensed drivers, and other approved sources. Names are drawn randomly from the list, and those people are summoned for jury service via post mail. Generally, any US citizen who is at least 18 years old and resides in Multnomah County is eligible for jury service, although excuses are granted to individuals who are older than 70 years old or breast-feeding, or who can demonstrate "undue hardship" or "extreme inconvenience". Oregon law provides that "the opportunity for jury service shall not be denied or limited on the basis of race, national origin, sex, age, religious belief, income, occupation or any other factor that discriminates against a cognizable group in this state" (source: Juror Information at Oregon Courts, http://www.ojd.state.or.us/jurorinfo/index. htm (accessed 12 January 2005)).

\section{RESULTS}

\section{Observational study results}

A total of 4287 cars and taxis were observed in motion. Of these vehicles, $1 \%(30 / 4287)$ had no head restraint on the driver's seat, 4\% (158/4287) had a fixed head restraint, and 95\% (4099/4287) had an adjustable head restraint (table 1).

Among the 158 cars with fixed head restraints, 21\% (33/ 158) of the head restraints were positioned optimally with the head touching the head restraint, and 79\% (125/158) were not. Among the vehicles with adjustable head restraints, only $7 \%(280 / 4099)$ were in optimal position. Forty six percent (1870/4099) of adjustable head restraints were in good vertical position but were suboptimal in the horizontal plane, whereas 47\% (1949/4099) were malpositioned in both the vertical and horizontal planes. Drivers with optimally positioned head restraints accounted for 7\% (313/4287) of all drivers, whereas 93\% (3974/4287) of drivers had suboptimally positioned head restraints (table 1 ).

Table 1 Head restraint positions of drivers in Portland, Oregon

\begin{tabular}{|c|c|c|c|}
\hline & Total & $\mathbf{n}$ & $\%$ \\
\hline No head restraint & 30 & & \\
\hline Suboptimal position & & 30 & 100 \\
\hline Fixed head restraint & 158 & & \\
\hline Optimal position & & 33 & 21 \\
\hline Suboptimal position & & 125 & 79 \\
\hline Adjustable head restraint & 4099 & & \\
\hline Optimal position & & 280 & 7 \\
\hline \multicolumn{4}{|c|}{ Suboptimal position in horizontal dimension } \\
\hline Optimal vertical height & & 1870 & 46 \\
\hline Suboptimal vertical height & & 1949 & 48 \\
\hline Total observed head restraints & 4287 & & \\
\hline Optimal position & & 313 & 7 \\
\hline Subontimal position & & 3974 & 93 \\
\hline
\end{tabular}

Table 2 Head restraint questionnaire results

\begin{tabular}{lc}
\hline & $\mathrm{n}=51(\%)$ \\
\hline $\begin{array}{lc} \\
\text { What type, if any, is your headrest? }\end{array}$ \\
$\begin{array}{l}\text { None (the car I drive does not have one) } \\
\text { Fixed }\end{array}$ & $2(4 \%)$ \\
Adjustable & $18(35 \%)$ \\
Is there a function for the headrest? & $10(20 \%)$ \\
Comfort (to rest one's neck muscles) & $38(75 \%)$ \\
Safety (to prevent neck injuries) & $3(6 \%)$ \\
Cosmetic (enhance the appearance of the car's interior) \\
Have you ever adjusted the headrest in your own car? \\
No & $28(55 \%)$ \\
Yes & $23(45 \%)$ \\
If so, how often? & $7(23 \%)$ \\
Once & $13(42 \%)$ \\
Occasionally (2-5 times) & $0(0 \%)$ \\
Every time I drive & $3(10 \%)$ \\
Other (please specify) & $1(2 \%)$ \\
Where should the top portion of the headrest be? & $12(24 \%)$ \\
Just below the neck & $35(69 \%)$ \\
In the middlle of the neck & $3(6 \%)$ \\
At the level of the head/skull & \\
Don't know & \\
How far away should the back of your head be from the & \\
headrest when driving? & $19(37 \%)$ \\
Touching the back of the head & $28(55 \%)$ \\
5 inches away from the head & $1(2 \%)$ \\
10 inches away from the head & $3(6 \%)$ \\
Don't know & \\
\hline & \\
\hline & \\
\hline &
\end{tabular}

\section{Questionnaire results}

A total of 56 Portland residents were asked to fill out a questionnaire regarding head restraint use. Five people declined, giving a decline rate of $10 \%(5 / 56)$ (see table 2 ).

\section{DISCUSSION}

To prevent whiplash injuries, car head restraints must be optimally positioned behind and close to the head. Currently, only a small proportion of drivers $(7 \%)$ meet these standards in Portland, Oregon. Fixed head restraints were three times more likely to be optimally positioned than adjustable head restraints $(21 \% \vee 7 \%)$. This is because fixed head restraints are designed to be in an optimal position with minimal to no adjustment, whereas adjustable head restraints can be positioned in variable positions, increasing the likelihood of a suboptimal position. Most Portland residents polled understood the function and effective positioning of head restraints. This discrepancy between actual practice and understanding should be addressed with public education and, potentially, manufacturer design changes that place the head restraints in a more optimal position-behind and close to the head.

\section{Optimal $v$ suboptimal head restraint position}

The results of this study showed that the majority of observed drivers in Portland, Oregon had suboptimally positioned head restraints $(79 \%$ of fixed and $93 \%$ of adjustable head restraints). Our finding that only $7 \%$ of adjustable head restraints were in optimal position is in general agreement with two similar studies. Jeroshch et al defined "optimal" horizontal distance between the back of the head and head restraint as being $0 \mathrm{~cm}$, with only $7.4 \%$ of drivers falling into this category. ${ }^{16}$ Viano et al showed in HYGE sled tests with a Hybrid III dummy that the position providing the least amount of neck extension was with a head restraint positioned above the ear (vertical) and less than 2 inches from the back of the head (horizontal). ${ }^{11}$ Based on these data Viano et al defined a favorable head restraint position in field observations of drivers of moving vehicles as a head restraint above the ears and less than 4 inches from the back of the 
head. Despite including all types of vehicles, their results were similar to ours; they calculated that only $10 \%$ of drivers had head restraints in the most favorable position. ${ }^{11}$

\section{Fixed $v$ adjustable head restraints}

Head position for fixed head restraints was assessed only for the horizontal dimension. This was done based on the following assumption: fixed head restraints are designed with a large vertical height with the intent that no adjustment is necessary. In this study, fixed head restraints were three times as likely as adjustable head restraints to be in optimal position $(21 \% \vee 7 \%)$ because vertical position was controlled. This demonstration of superior positioning of fixed head restraints is supported by studies demonstrating superior efficacy. Nygren et al found that fixed head restraints decreased neck injuries in rear-end collisions by $24.5 \%$, whereas adjustable head restraints decreased them by $14.8 \% .^{17}$

\section{Barriers to proper head restraint positioning}

We believe that the two largest barriers to proper head restraint positioning are (1) inadequate head restraint design, and (2) lack of public awareness.

\section{INADEQUATE HEAD RESTRAINT DESIGN}

In this study, $93 \%$ and $79 \%$ of drivers with adjustable and fixed head restraints, respectively, had some element of horizontal distance between the head and the head restraint. Although our definition of optimal position was more stringent than that defined by the IIHS, it is clear that head restraint positioning can be improved. One inherent problem is that people tend to drive with a head position that is either perfectly vertical or bent slightly forward. Car manufacturers could make a tremendous impact by creating either an intrinsic forward angle within the head restraint itself or a mechanism for adjusting the horizontal dimension. Ironically, some head restraints become further from the head as they are adjusted upwards. Several novel seat back and head restraint designs have been made by car manufacturers in recent years in an attempt to place the head restraint behind and close to the head in rear-end collisions. One such design by Saab, called "The Saab Active Restraint", is activated by the weight and movement of the body in a rear-end collision, which force the padded head restraint up and toward the head. ${ }^{7}$ As stated above, active head restraint design changes in Saab, General Motors, and Nissan vehicles have resulted in a $43 \%$ reduction in neck injury claims. ${ }^{8}$

\section{Public awareness}

Seventy five percent of polled Portland residents understood that head restraints are safety devices. Sixty nine percent of people identified the proper vertical height for a head restraint; however, only $37 \%$ thought that the head restraint should be touching the back of the head. Our study shows a large discrepancy between understanding and actual usage. This failure to practice safety precautions is probably related to a lack of public awareness on the effectiveness of head restraint positioning in preventing whiplash.

A similar dilemma faced healthcare providers in Seattle, Washington trying to prevent head injuries through the use of bicycle helmets. In 1986, researchers in Seattle launched a community wide information campaign designed to increase helmet use among bicycle riders. ${ }^{18} 19$ As a result, helmet use increased and admissions for severe head injuries decreased..$^{18}$ We are proposing a similar citywide campaign to increase awareness of optimal head restraint position. Although addressing manufacturer design is not the focus of this campaign, it is hoped that consumer awareness will

\section{Key points}

- To prevent whiplash injuries, car head restraints must be correctly positioned behind and close to the head.

- $93 \%$ of all head restraints observed were not positioned optimally.

- Fixed head restraints were three times more likely to be in optimal position versus adjustable head restraints (21\% v 7\%).

- $75 \%$ polled Portland residents understood the function and effective positioning of head restraints.

- The discrepancy between actual practice and understanding should be addressed with public education and improvement in head restraint design.

ultimately place pressure on car manufacturers to implement better head restraints.

\section{Study limitations}

The limitations of this study are in data recording, our definition of optimal head restraint position, and the small number of people queried on proper head restraint use. Specifically, we did not record the time of day or location of observed drivers. These data are crucial in making any conclusions about different driving patterns that drivers may have at various times of day or in different neighborhoods. For example, time of day would have an effect on the type of driver observed (for example, rush hour traffic would include commuters, whereas midday observations would capture people running errands). Unfortunately, we are unable to comment on these subpopulations of drivers. Approximately equal amounts of time were spent counting cars at each location, although the exact number of cars counted at each location was not recorded. Also, no internal validity was accomplished to validate the consistency of our single observer (that is, a single observer recorded all the head restraint data on moving cars).

For ease of observation, our definition of optimal head restraint positioning is stricter than that of the IIHS. The IIHS recommends no more than four inches from the head to the back of the head restraint. ${ }^{12}$ Therefore, our data may underestimate the number of drivers who have a good head restraint position in the horizontal dimension based on the IIHS definition. ${ }^{12}$

Our questionnaire had a very small number of respondents because of the size of the jury pool, thus making it difficult to draw any formal conclusions. Furthermore, our questionnaire did not collect demographic data (sex, age, annual income, etc) and thus we cannot confirm that our sample is representative of the population of Portland. Finally, the manner in which we phrased our questions may have been misleading. Specifically, our questionnaire used the term "headrest" instead of "head restraint". This was done in an attempt to keep the respondent from deducing the correct answers based on the term "head restraint". However, this terminology may have misled respondents. Finally, the questionnaire did not define the term "fixed" headrest. This lack of definition may explain the large discrepancy between observed fixed head restraints and people answering that their head restraint is fixed ( $4 \% v 35 \%)$.

\section{CONCLUSION}

To prevent whiplash injuries, car head restraints must be correctly positioned behind and close to the head. Currently, only a small proportion of drivers meet these standards in 
Portland, Oregon. Most Portland residents polled understood the function and effective positioning of head restraints. This discrepancy between actual practice and understanding should be addressed with public education and possibly manufacturer design changes that place the head restraints in a more optimal position: behind and close to the head.

\section{ACKNOWLEDGMENTS}

We thank Kristin Kraus for her excellent editorial guidance in preparing this paper. The authors have no competing interests to declare.

\author{
Authors' affiliations \\ A L Young, B T Ragel, E H Frank, Department of Neurosurgery, Oregon \\ Health Sciences University, Portland, OR, USA \\ E Su, C N Mann, Department of Emergency Medicine, Oregon Health \\ Sciences University, Portland, OR, USA \\ B T Ragel, Department of Neurosurgery, University of Utah, Salt Lake \\ City, UT, USA
}

\section{REFERENCES}

1 Farmer CM, Wells JK, Werner JV. Relationship of head restraint positioning to driver neck injury in rear-end crashes. Accid Anal Prev 1999;31:719-28.

2 O'Neill B, Haddon W Jr, Kelley AB, et al. Automobile head restraints frequency of neck injury claims in relation to the presence of head restraints. Am J Public Health 1972;62:399-406.

3 Quinlan KP, Annest JL, Myers B, et al. Neck strains and sprains among motor vehicle occupants - United States, 2000. Accid Anal Prev 2004;36:21-7.

4 States JD, Balcerak JC, Williams JS, et al. Injury frequency and head restraint effectiveness in rear-end impact accidents. Proceedings of the 16th Stapp Car Crash Conference, 1972:228-45.

5 Spitzer WO, Skovron ML, Salmi LR, et al. Scientific monograph of the Quebec Task Force on Whiplash-Associated Disorders: redefining "whiplash" and its management [see comments]. Spine. 1995;20(8 Suppl): 1S-73S, [Published erratum appears in Spine 1995;20:2372.].

6 Injuries in auto accidents: an analysis of auto insurance claims. 1999:1-170.

7 IIHS. Special issue: neck injuries in rear-end crashes. Status Report: Insurance Institute for Highway Safety 1999;34:1-11.

8 IIHS. Not your father's head restraint. Not your mother's either. Status Report: Insurance Institute for Highway Safety 2002;37:1-3.

9 Svensson MY, Lovsund $P$, Haland $Y$, et al. The influence of seat-back and head-restraint properties on the head-neck motion during rear-impact. Accid Anal Prev 1996;28:221-7.

10 Tencer AF, Mirza S, Bensel K. Internal loads in the cervical spine during motor vehicle rear-end impacts: the effect of acceleration and head-to-head restraint proximity. Spine 2002;27:34-42.

11 Viano DC, Gargan MF. Headrest position during normal driving: implication to neck injury risk in rear crashes. Accid Anal Prev 1996;28:665-74.

12 IIHS. Head restraint ratings. Status Report: Insurance Institute for Highway Safety 2003;38:4.

13 Fox JC, Williams JF. Mathematical model for investigating combined seatback-head restraint performance during rear-end impact. Med Biol Eng 1976;14:263-73.

14 Tencer AF, Mirza S, Bensel K. The response of human volunteers to rear-end impacts: the effect of head restraint properties. Spine 2001;26:2432-40, discussion 2441-2.

15 Chapline JF, Ferguson SA, Lillis RP, et al. Neck pain and head restraint position relative to the driver's head in rear-end collisions. Accid Anal Prev 2000;32:287-97.

16 Jerosch J, Ruth S, Thorwesten L. Automobile head supports-adjustment possibilities and utilization. Results of a field study [in German]. Unfallchirurg, 1997; 100, 561-7.

17 Nygren A. Injuries to car occupants-some aspects of the interior safety of cars. A study of a five-year material from an insurance company. Acta OtoLaryngol Supplement 1984;395:1-164.

18 Mock CN, Maier RV, Boyle E, et al. Injury prevention strategies to promote helmet use decrease severe head injuries at a level I trauma center. J Trauma 1995;39:29-33, discussion 34-5.

19 Rivara FP, Thompson DC, Patterson MQ, et al. Prevention of bicycle-related injuries: helmets, education, and legislation. Ann Rev Public Health $1998 ; 19: 293-318$. 